\title{
Gonadotrophin-releasing Hormone Treatment for Induction of Follicular Maturation and Ovulation in Amenorrhoeic Women with Anorexia Nervosa
}

\author{
SVEN JOHAN NILLIUS, LEIF WIDE
}

British Medical fournal, 1975, 3, 405-408

\begin{abstract}
Summary
Follicular maturation and ovulation can be induced in amenorrhoeic women with anorexia nervosa by longterm treatment with $500 \mu \mathrm{g}$ of luteinizing hormone releasing hormone (LH-RH) every eight hours. In some women, however, treatment with LH-RH alone results in ovulatory menstrual cycles with indications of luteal phase insufficiency. Human chorionic gonadotrophin (HCG) was therefore given with LH-RH during three treatment cycles. This resulted in ovulation and normal corpus-luteum function, as shown by the occurrence of a single pregnancy in the only involuntarily sterile patient.

During the prolonged LH-RH treatment the LH response to LH-RH increased in parallel with the increased oestrogen secretion while the follicle-stimulating hormone response to LH-RH decreased. These changes in the pituitary responsiveness to LH-RH may result from modulating effects on the pituitary by the sex steroids.
\end{abstract}

\section{Introduction}

The exciting possibility of using luteinizing hormone releasing hormone (LH-RH) for treating infertility has been much explored recently. Therapeutic studies with LH-RH in anovulatory women were reviewed by Schally et al., ${ }^{1}$ who concluded that, though ovulation could be induced with $\mathrm{LH}-\mathrm{RH}$ in sterile women, the percentage of ovulations and pregnancies was relatively low. The best results were obtained in clomipheneresponsive women with the Stein-Leventhal syndrome ${ }^{2}$ or anovulatory cycles $^{3}$-that is, in women who usually have evidence of endogenous ovarian activity. The first therapeutic studies with LH-RH in men with oligospermia were not successful, ${ }^{4}$ but puberty, potency, and spermatogenesis have been successfully induced in hypogonadal men with hypothalamic or pituitary dysfunction with long-term treatment with $500 \mu \mathrm{g}$ LH-RH every eight hours. ${ }^{5}$ This therapeutic regimen also induced follicular maturation in clomiphene-unresponsive amenorrhoeic women. ${ }^{6}{ }^{7}$

We have induced both follicular maturation and ovulation in four women with anorexia nervosa and secondary amenorrhoea. ${ }^{7}$ Low progesterone levels during the luteal phase of the induced cycle in two of the women, however, suggested that they may have had an insufficient corpus-luteum function. We present here the results of further studies on ovulation induction with LH-RH in three women with anorexia nervosa and amenorrhoea. LH-RH was combined with injections of human chorionic gonadotrophin (HCG) to ensure ovulation and normal corpus-luteum function.

\footnotetext{
Departments of Obstetrics and Gynaecology and Clinical Chemistry, University Hospital, Uppsala, Sweden

SVEN JOHAN NILLIUS, M.D., PH.D., Assistant Professor

LEIF WIDE, M.D. PH.D., Assistant Professor
}

\section{Patients and Methods}

Detailed clinical and hormonal studies were performed in three women aged 20 to 28 years during long-term treatment with LH-RH for induction of follicular maturation and ovulation. All the women had had anorexia nervosa and secondary amenorrhoea for 18 months to 13 years. No organic cause of the amenorrhoea and weight loss was found at the gynaecological and endocrinological investigation. Buccal-smear chromatin complement showed a normal female pattern. $X$-ray examinations of the skull and pituitary fossa showed nothing abnormal. All the patients were euthyroid, as judged by clinical examination and thyroid function tests. The 24-hour urinary excretion of 17-hydroxycorticosteroids and 17-ketosteroids was norma except in one patient (case 3), who had low basal levels which increased normally after metyrapone. Her cortisol levels in plasma were within the normal range and increased normally after corticotrophin and vasopressin.

All the patients had absent endogenous oestrogen production as judged by indirect clinical methods for estimating oestrogenic activity on target organs and direct measurements of oestrogen levels in blood and urine. Anorexia nervosa was diagnosed by a psychiatrist according to Bruch's criteria. ${ }^{8}$

Hormone Assay Methods.-Immunoreactive follicle-stimulating hormone (FSH) and $\mathrm{LH}$ in serum were determined by a radioimmunosorbent technique. ${ }^{9}$ Immunoreactive oestradiol in serum was determined by a radioimmunological technique using an antiserum to oestradiol-6-oxime. ${ }^{10}$ Progesterone was assayed by a similar radioimmunological method. The 24-hour urinary excretion of total oestrogens were measured (as oestriol), according to the rapid method of Brown et al. ${ }^{11}$

$L H-R H$ Treatment.-Diagnostic tests with LH-RH were performed with an intravenous dose of $100 \mu \mathrm{g}$ of LH-RH (Hoechst). ${ }^{12}$ The FSH and LH response to LH-RH was defined as the difference between the mean of the two values 30 and 45 minutes after the LH-RH injection and the mean of the two control values. Long-term treatment with $500 \mu \mathrm{g}$ of LH-RH every eight hours was then started. The 500- $\mu \mathrm{g}$ dose was dissolved in $1 \mathrm{ml}$ of distilled water and injected intramuscularly or subcutaneously. During treatment venous blood samples were obtained at frequent intervals and assayed for $\mathrm{FSH}, \mathrm{LH}$, oestradiol, and progesterone. The 24-hour urinary excretion of total oestrogens was also determined during part of the treatment.

\section{Results}

Basal gonadotrophin levels and gonadotrophin responses to LH-RH before the LH-RH treatment are shown in table I. The pretreatment LH levels were below normal in all the women, though only one of

Pretreatment Gonadotrophin Levels and Gonadotrophin Responses to Intravenous Injection of $100 \mu \mathrm{g} \mathrm{LH}-\mathrm{RH}$

\begin{tabular}{|c|c|c|c|c|c|c|c|c|}
\hline \multirow{2}{*}{$\begin{array}{l}\text { Case } \\
\text { No. }\end{array}$} & \multirow{2}{*}{$\begin{array}{l}\text { Height } \\
(\mathrm{cm})\end{array}$} & \multirow{2}{*}{$\underset{(\mathrm{kg})}{\text { Weight }}$} & \multicolumn{2}{|c|}{$\mathrm{FSH}(\mu \mathrm{g} / \mathrm{l})$} & \multicolumn{2}{|c|}{$\mathrm{LH}(\mu \mathrm{g} / \mathrm{l})$} & \multicolumn{2}{|c|}{ FSH/LH Ratio } \\
\hline & & & Basal & $\begin{array}{c}\text { Response } \\
\text { to } \\
\text { LH-RH }\end{array}$ & Basal & $\begin{array}{c}\text { Response } \\
\text { to } \\
\text { LH-RH }\end{array}$ & Basal & $\begin{array}{c}\text { Response } \\
\text { to } \\
\text { LH-RH }\end{array}$ \\
\hline $\begin{array}{l}1 \\
2 \\
3\end{array}$ & $\begin{array}{l}160 \\
165 \\
166\end{array}$ & $\begin{array}{l}47 \\
41 \\
37\end{array}$ & $\begin{array}{l}0.95 \\
0.41 \\
0.83\end{array}$ & $\begin{array}{l}1 \cdot 3 \\
1.4 \\
3 \cdot 3\end{array}$ & \begin{tabular}{|l|}
$0 \cdot 39$ \\
$0 \cdot 16$ \\
$0 \cdot 29$
\end{tabular} & $\begin{array}{l}2 \cdot 2 \\
0.3 \\
1 \cdot 4\end{array}$ & \begin{tabular}{|l|}
2.43 \\
2.56 \\
2.86
\end{tabular} & $\begin{array}{l}0.59 \\
4.66 \\
2.35\end{array}$ \\
\hline Mean & & & 0.73 & $2 \cdot 0$ & 0.28 & $1 \cdot 3$ & $2 \cdot 61$ & 2.53 \\
\hline $\begin{array}{l}\text { Control } \\
\text { mean } \\
\text { (and } \\
\text { range)* }\end{array}$ & & & $\begin{array}{c}1 \cdot 22 \\
(0 \cdot 66- \\
2 \cdot 2) \dagger\end{array}$ & $\begin{array}{c}0.31 \\
(0- \\
1 \cdot 1) \ddagger\end{array}$ & $\begin{array}{c}1 \cdot 23 \\
(0 \cdot 46- \\
3 \cdot 3) \dagger\end{array}$ & $\begin{array}{c}1.4 \\
(0 \cdot 67- \\
3 \cdot 5) \ddagger\end{array}$ & 0.99 & 0.22 \\
\hline
\end{tabular}

* Follicular phase of menstrual cycle.

tFrom Nillius and Wide. ${ }^{12}$ 
them had a pathologically low basal FSH value. They all responded with significant increases in serum gonadotrophin levels after LH-RH administration. Two patients (cases 2 and 3) had much higher FSH than $\mathrm{LH}$ responses to LH-RH. Both these patients were still below their ideal weight when investigated. The LH response in case 1 , however, was more pronounced than the FSH response; this patient had regained her normal weight at the time of the study. She had been investigated with the LH-RH test 13 months earlier, when she weighed $39 \mathrm{~kg}$, and her basal FSH and LH levels $(0.44$ and $0.27 \mu \mathrm{g} / 1$ respectively) and $\mathrm{FSH}$ and $\mathrm{LH}$ response to $\mathrm{LH}-\mathrm{RH}(0.41$ and 0.31 $\mu \mathrm{g} / \mathrm{l}$ respectively) were then lower.

Results from the four treatment cycles are shown in figs. 1-4. One patient (case 1) self-administered $500 \mu \mathrm{g}$ of LRH subcutaneously every eight hours over four weeks (fig. 1). The oestrogen and progesterone patterns in blood during the treatment cycle were similar to those seen during ovulatory menstrual cycles. An endometrial biopsy on the 22nd day of treatment showed normal secretory changes. Menstrual bleeding occurred 15 days after the first observed increase of plasma progesterone. The progesterone levels in blood during the luteal phase were low, however, which may have indicated a minor insufficiency of corpus-luteum function.

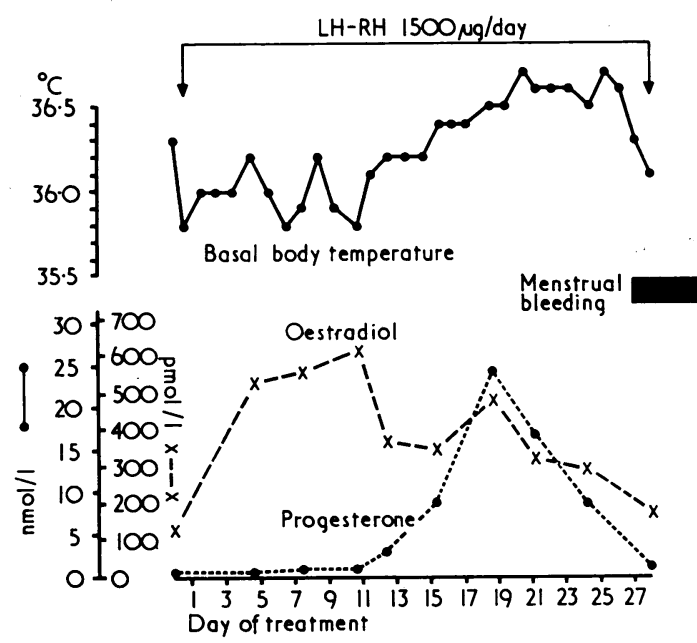

FIG. 1-Case 1. Basal body temperature and blood levels of oestradiol and progesterone during prolonged LH-RH treatment.

Conversion: SI to Traditional Units-Progesterone: $1 \mathrm{nmol} / 1 \approx 0.32 \mathrm{ng} / \mathrm{ml}$. Oestradiol: $1 \mathrm{pmol} / 1 \approx 0.27 \mathrm{pg} / \mathrm{ml}$.

The patient in case 2 was therefore given supplementary injections of HCG during the postovulatory phase of her LH-RH treatment cycle to ensure adequate corpus-luteum function (fig. 2). A single intramuscular injection of $9000 \mathrm{IU}$ of $\mathrm{HCG}$ was given when urinary oestrogen excretion was $208 \mathrm{nmol} / 1(60 \mu \mathrm{g} / 24 \mathrm{~h})$ - that is, at a level consistent with full follicular maturation. The $\mathrm{LH}-\mathrm{RH}$ injections were interrupted on day 21 and one week later a second injection of 6000 IU of HCG was given. The blood level of oestradiol increased parallel to the oestrogen excretion in urine and reached a peak of $789 \mathrm{pmol} / \mathrm{l}(215 \mathrm{pg} / \mathrm{ml})$ two days before HCG was given. This peak was followed by a fall and at the same time the plasma progesterone level increased to $13.4 \mathrm{nmol} / 1(4.2 \mathrm{ng} / \mathrm{ml})$ when $\mathrm{HCG}$ was given. Thus, ovulation presumably occurred at that time. This combined treatment with LH-RH and HCG resulted in a perfectly normal luteal phase progesterone curve with a plateau-like maximum around $63.6 \mathrm{nmol} / 1(20 \mathrm{ng} / \mathrm{ml})$ and a duration of 15 days.

Before treatment this patient had responded to $\mathrm{LH}-\mathrm{RH}$ with a small LH increase and an FSH increase which was nearly five times the LH increase (table I). After 16 days of treatment with LH-RH the response pattern to $\mathrm{LH}-\mathrm{RH}$ changed dramatically: the $\mathrm{LH}$ response was pronounced and there was no longer any appreciable FSH response. The blood oestradiol level was nearly 10 times the pretreatment level. Two days later administration of $500 \mu \mathrm{g}$ of $\mathrm{LH}-\mathrm{RH}$ resulted in an $\mathrm{LH}$ increase up to $5.7 \mu \mathrm{g} / \mathrm{l}$-that is, to the level comparable with a low normal mid-cycle peak level in the ovulatory menstrual cycle. Increased progesterone levels were observed.

The third patient, who was involuntarily sterile, was treated twice (figs. 3 and 4). Follicular growth and maturation were induced by

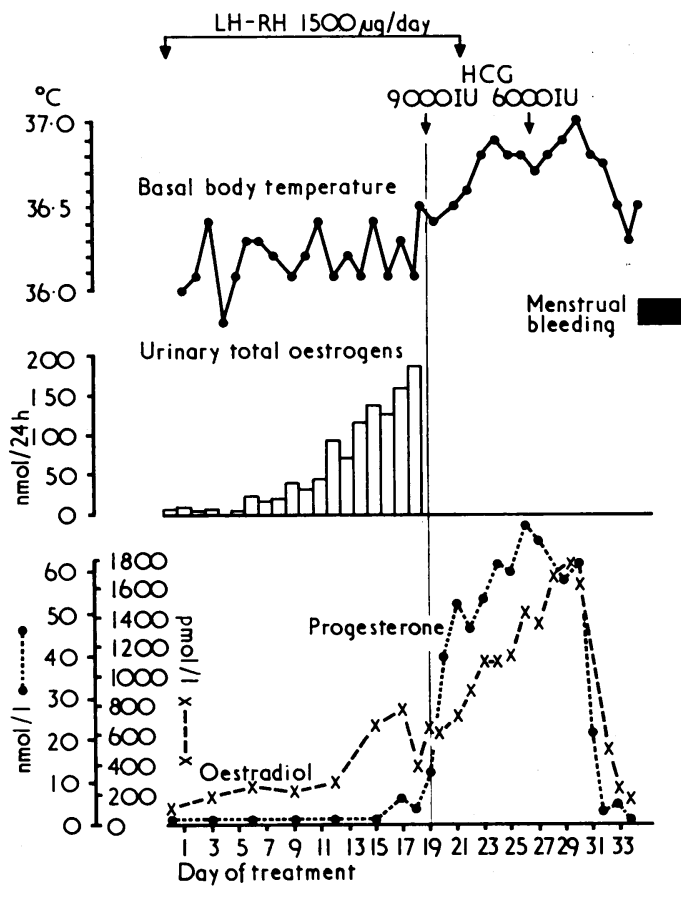

FIG. 2-Case 2. Basal body temperature, total urinary oestrogen excretion, and blood levels of oestradiol and progesterone during LH-RH treatment Conversion: SI to Tradiiional Units-Total oestrogens (as oestriol): $1 \mathrm{nmol} /$ $24 \mathrm{~h} \approx 0.29 \mu \mathrm{g} 24 \mathrm{~h}$.

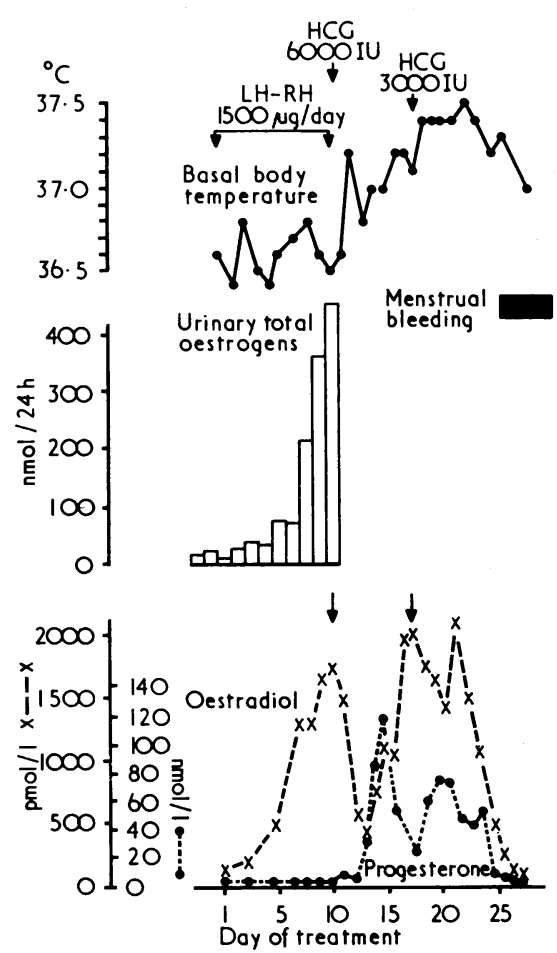

FIG. 3-Case 3. Basal body temperature, total urinary oestrogen excretion, and blood levels of oestradiol and progesterone during first LH-RH treatment cycle.

LH-RH alone. Ovulation was triggered by HCG, which was also given during the postovulatory period to support luteal function. Conception occurred during the second treatment course (fig. 4). At the time of writing the pregnancy had been uneventful ( 28 weeks) and $x$-ray examination showed the presence of one fetus. Before the first treatment the FSH response to LH-RH was pronounced in this patient (case 3) (table I). After nine days of LH-RH treatment when the oestradiol level in blood had risen from 114 to $1755 \mathrm{pmol} / 1$ $(31-478 \mathrm{pg} / \mathrm{ml})$, there was no longer any FSH response, but the LH 

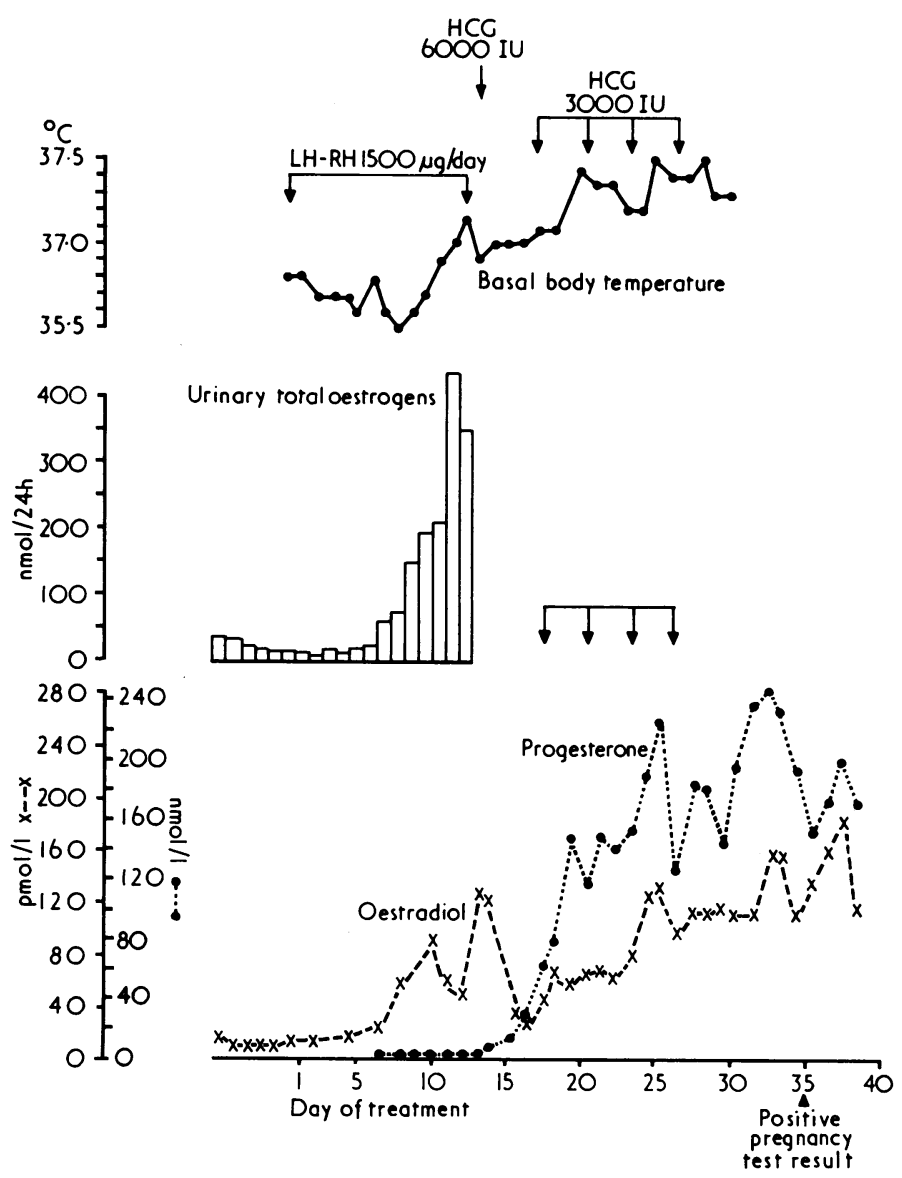

FIG. 4-Case 3. Basal body temperature, total urinary oestrogen excretion, and blood levels of oestradiol and progesterone during second LH-RH treatment cycle.

response was augmented. When the second treatment was started on the seventh day of menstrual bleeding after the first treatment course only a small FSH increase was seen after intravenous LH-RH. The FSH response increased considerably during the first four days of treatment; then it progressively decreased. On the 10 th day of treatment there was no longer any FSH response to LRH. The LH response increased during the treatment.

No untoward effects of the prolonged LH-RH treatment were observed.

\section{Discussion}

In 1974 Mortimer et al. ${ }^{5}$ introduced treatment with much higher doses of LH-RH than had been used before. In amenorrhoeic women with anorexia nervosa without evidence of endogenous ovarian activity both follicular maturation and ovulation could be induced by prolonged treatment with $500 \mu \mathrm{g}$ of LH-RH every eight hours. ${ }^{6}$ ? In these studies characteristic changes in the oestrogen and progesterone levels were used as presumptive evidence of ovulation. Such values are only indirect indicators of ovulation, however. Pregnancy, an irrefutable proof of ovulation, has not been reported after high-dose LH-RH treatment.

In our study an infertile clomiphene-unresponsive woman with a 13-year history of secondary amenorrhoea became pregnant after she had been treated with LH-RH. This woman had previously been given 10 treatment courses with human gonadotrophins (HMG). The last treatment course resulted in a multiple pregnancy which ended in abortion of quadruplets. During the next treatment cycle HMG was replaced by LH-RH for induction of follicular growth and maturation. This treatment was successful and resulted in a single pregnancy.
The LH-RH treatment in this woman was combined with HCG, which has prolonged LH activity. The reason for this was that three out of five women who had previously been treated with $500 \mu \mathrm{g}$ of LH-RH every eight hours over four weeks had shown signs which suggested insufficient corpus-luteum function. For normal luteal function it seems essential to have (a) adequate FSH stimulation early in the cycle for growth of the follicles, (b) adequate $\mathrm{LH}$ surge for luteinization of granulosa cells after ovulation, and (c) minimal residual $\mathrm{LH}$ in the luteal phase of the cycle. ${ }^{13}$ During the normal menstrual cycle LH secretion increases dramatically in mid-cycle. This mid-cycle surge of LH is presumably responsible for ovulation and corpusluteum formation. Some women treated with LH-RH may be unable to produce the changes in the hypothalamic-pituitary system which are behind this great preovulatory $\mathrm{LH}$ increase and they may therefore need additional LH or HCG to ovulate and provide normal hormonal support for corpus-luteum formation and function.

During the LH-RH treatment interesting changes in the pituitary responsiveness to LH-RH occurred in two women. Both showed augmented LH responses to LH-RH after induction of follicular maturation with increased oestrogen secretion. In one (case 2) the LH level after LH-RH administration reached a low normal mid-cycle peak level, and she presumably ovulated, as the plasma progesterone levels increased. The other women (case 3) had LH increases at follicular maturation up to the lower limit of the normal mid-cycle peak, but she did not ovulate before HCG was given. She had obviously had an adequate FSH stimulation early in the cycle with normal follicular growth and maturation since she became pregnant during the treatment cycle.

The FSH response to LH-RH decreased during the LH-RH treatment while the oestrogen secretion from the ovary increased. When the follicle reached maturity there was no longer any significant FSH increase after LH-RH administration. These changes in the FSH response to $\mathrm{LH}-\mathrm{RH}$, which are probably caused by steroid modulation on the pituitary, may give $\mathrm{LH}-\mathrm{RH}$ treatment an advantage over HMG treatment for induction of follicular growth and maturation. HMG treatment is effective but has serious drawbacks: complications of HMG treatment, such as the severe hyperstimulation syndrome and multiple pregnancies, result from excessive stimulation of the ovaries. The ovarian response to gonadotrophins should be monitored by daily oestrogen determinations to prevent these complications, and the daily dose of HMG individually adjusted accordingly to avoid overstimulation. During LH-RH treatments the intact feedback system between the pituitary and the ovarian steroids may automatically prevent excessive FSH stimulation. High oestrogen levels seem to diminish the pituitary FSH response to LH-RH in amenorrhoeic women and this mechanism may, we hope, prevent hyperstimulation during prolonged treatment with high doses of LH-RH.

All the seven women whom we have treated successfully with LH-RH so far have had amenorrhoea because of anorexia nervosa. They had relatively high FSH responses to LH-RH before treatment. Such prepubertal-like response patterns to LH-RH may be favourable for initiating follicular growth and maturation. Nevertheless, the patient in case 1 , who had a LH response twice as high as the FSH response to $\mathrm{LH}-\mathrm{RH}$ before treatment, responded to LH-RH treatment with both follicular maturation and ovulation. This patient had reverted to the adult response pattern to $\mathrm{LH}-\mathrm{RH}$ after she had gained weight. During prolonged LH-RH treatment the $\mathrm{LH}$ response became more and more pronounced in the other two patients and they reverted to the adult response pattern to $\mathrm{LH}-\mathrm{RH}$.This finding, which we had observed before, ${ }^{7}$ suggests that there is an absent or deficient hypothalamic secretion of LH-RH in patients with anorexia nervosa and body weights below normal.

Replacement of HMG by LH-RH would probably have many advantages. Hyperstimulation of the ovaries might be easier to prevent during LH-RH treatment; the intact feedback system between the pituitary and the ovaries represents an interna 
control mechanism which may automatically prevent excessive FSH stimulation of the ovaries. It should also be possible to produce synthetic LH-RH fairly cheaply. Nevertheless, many more clinical studies must be performed before we can define the proper place for LH-RH in the treatment of anovulatory infertility. Our studies in patients with anorexia nervosa prove that LH-RH can be used alone or in combination with HCG to induce follicular growth and maturation, ovulation, and pregnancy in such amenorrhoeic women, who have no evidence of endogenous ovarian activity. It remains to be seen if LH-RH is equally effective in other women with amenorrhoea.

This work was supported by the Swedish Medical Research Council (grant No. 13X-3145).

We thank Dr. Franz Enzmann, Farbwerke Hoechst AG, for generously supplying LH-RH; Assistant Professor Hans Fries for help and advice; Mrs. Anna-Lena Barmark, Mrs. Birgitta Bohman, Mrs. Ann Sandberg, and Miss Kerstin Wall for skilful technical help; and the nurses and secretaries at the gynaecological wards of the department of obstetrics and gynaecology, University Hospital, Uppsala, for their kind help.
Requests for reprints should be addressed to Dr. Sven Johan Nillius, Department of Obstetrics and Gynaecology, University Hospital, S-750 14 Uppsala, Sweden.

\section{References}

1 Schally, A. V., Kastin, A. J., and Arimura, A., American fournal of Obstetrics and Gynecology, in press.

2 Zarate, A., et al., Fertility and Sterility, 1974, 25, 3.

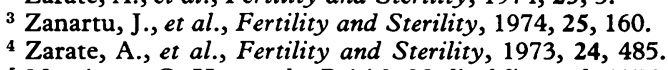

5 Mortimer, C. H., et al., British Medical fournal, 1974, 4, 617.

${ }^{6}$ Mortimer, C. H., Besser, G. M., and McNeilly, A. S., Proceedings of the Serono Symposium on Hypothalamic Hormones (Milan, 14-16 October, 1974), in press.

7 Nillius, S. J., Fries, H., and Wide, L., American fournal of Obstetrics and Gynecology, in press.

${ }^{8}$ Bruch, H., International Psychiatry Clinics, 1970, 7, 3.

9 Wide, L., et al., Acta Endocrinologica (Kфbenharn), 1973, Suppl. 174, p. 1.

10 Lindberg, B. S., et al., Acta Obstetricia et Gynecologica Scandinavica, 1974, Suppl. 32, p. 5.

11 Brown, J. B., et al., Fournal of Endocrinology, 1968, 42, 5.

12 Nillius, S. J., and Wide, L., Fournal of Obstetrics and Gynaecology of the British Commonwealth, 1972, 79, 865.

13 Jones, G. S., Clinical Obstetrics and Gynecology, 1973, 16, 255.

\section{Urinary $\mathrm{N}$-acetyl- $\boldsymbol{\beta}$-D-glucosaminidase Activities in Patients with Renal Disease}

\section{J. M. WELLWOOD, B. G. ELLIS, R. G. PRICE, K. HAMMOND, A. E. THOMPSON, N. F. JONES}

British Medical fournal, 1975, 3, 408-411

\begin{abstract}
Summary
Urinary $\boldsymbol{N}$-acetyl- $\beta$-D-glucosaminidase (NAG) activities were assayed in every urine void throughout 24 hours in 17 normal people and in four patients with renal disease. The variation in NAG activity due to changing rates of urine flow was almost eliminated by factoring enzyme activity by the urinary creatinine concentration. Random samples of urine may thus be used for assay. The results of NAG assay in 36 patients with acute and chronic renal diseases showed that NAG was a sensitive indicator of renal damage. This simple test may be valuable in detecting or monitoring renal disease.
\end{abstract}

\section{Introduction}

The fluorimetric assay of urinary $\beta$-glycosidases using 4methyl-umbelliferyl substrates ${ }^{1}$ is simple and suitable for routine hospital laboratories. Increased enzyme activities have been found in the urine in some human renal diseases ${ }^{2} 3$ and after kidney surgery. ${ }^{4}$ More recently, we have reported increased

\section{St. Thomas's Hospital, London S.E.1}

J. M. WELLWOOD, M.A., F.R.C.S., Honorary Senior Registrar, Transplantation Unit (Present address: St. Bartholomew's Hospital, London E.C.1) B. G. ELLIS, PH.D., Medical Student

K. HAMMOND, M.R.C.P., Senior House Officer

A. E. THOMPSON, M.S., F.R.C.S., Consultant Surgeon and Director of Transplantation Unit

N. F. JONES, M.D., F.R.C.P., Consultant Physician

Queen Elizabeth College, University of London, London

R. G. PRICE, PH.D., Lecturer in Biochemistry urinary activity of $N$-acetyl- $\beta$-D-glucosaminidase (NAG) during episodes of acute rejection of renal allografts. ${ }^{5}$

Until now the measurement of urinary enzyme activity has entailed the collection of all urine over eight to 24 hours, ${ }^{6}$ ? and results have been expressed as the enzyme output in the collection period. By this means the effect of varying urine volumes on measured urine enzyme activity has been overcome, but in practice the inaccuracies involved in such collections of urine and the delay in obtaining a result have reduced the value of the test. We report here studies designed to test the validity of using "spot" urine samples for the assay of NAG and observations on urinary excretion of this enzyme in patients with various renal diseases.

\section{Patients and Methods}

Preparation of Samples.-Urine specimens were obtained from patients and normal subjects. Neither dialysis nor centrifugation of urine is necessary before enzyme assay. ${ }^{5}$ Assay was performed within 24 hours of collection. Urine samples were diluted twentyfold, and NAG activities were measured using a fluorimetric method. ${ }^{1}$ Urinary creatinine concentrations were measured by autoAnalyzer (Technicon) using the alkaline picrate method.

Normal Subjects.-Seventeen normal ambulant subjects (nine men and eight women) were studied throughout 24 hours. Urinary NAG and creatinine levels were measured in midstream aliquots of every void and the rate of urine flow calculated. Regression analysis was used to estimate the percentage variation in urinary NAG accounted for by several variables including the rate of urine flow. Urinary NAG activities were measured in a further 144 normal ambulant subjects who had no history of renal disease.

Patients.-Four patients with renal disease (chronic pyelonephritis, chronic glomerulonephritis, myeloma kidney, and diabetic nephropathy) were studied throughout 24 hours. Urinary NAG and creatinine levels were measured and the rates of urine flow leading up to each void calculated. A further 36 patients with acute or chronic renal diseases were studied on 116 occasions. Patients with acute renal disease included six with renal injury after episodes of hypotension 